\title{
Evaluation of Marginal Seal and Microleakage of a Sealant Modified with Silver Nanoparticles in Primary Molars: In Vitro Study
}

\section{Evaluación del Sellado Marginal y Microfiltración de un Sellador Modificado con Nanopartículas de Plata en Molares Primarios: Estudio In Vitro}

Elisa Morales Quiroga DDS ${ }^{1}$; Alan Martínez Zumarán DDS, MS²; Juan Francisco Hernández Sierra MD, MS³ Keila Alvarado Estrada MS ; Amaury Pozos Guillén DDS, PhD ${ }^{4}$

1. Resident, Pediatric Dentistry Postgraduate Program, Faculty of Dentistry, Universidad Autónoma de San Luis Potosí, México.

2. Professor, Pediatric Dentistry Postgraduate Program, Faculty of Dentistry, Universidad Autónoma de San Luis Potosí, México.

3. Professor, Clinical Epidemiology Postgraduate Program, Faculty of Medicine, Universidad Autónoma de San Luis Potosí, México.

4. Professor, Basic Sciences Laboratory, Faculty of Dentistry, Universidad Autónoma de San Luis Potosí, México.

Correspondence to: Dr. Amaury de Jesús Pozos Guillén - apozos@uaslp.mx

Received: 15-VI-2015

Accepted: 25-VI-2015

\section{ABSTRACT}

The objective of this study was to evaluate the marginal seal effectiveness and microleakage of a pit and fissure sealant containing silver nanoparticles (AgNPs). An experimental in vitro study was carried out using 40 extracted temporary molars without caries or incipient caries. These molars were divided into two groups: Group A (20 molars), to which a silver nanoparticle-containing sealant was applied, and Group B (20 molars), to which a conventional sealant was applied. The marginal seal and microleakage were evaluated. No significant differences in the marginal seal or microleakage were noted between the silver nanoparticle-containing sealant and the conventional sealant.The addition of AgNPs does not alter the adhesion or resistance of the sealant.

\section{KEYWORDS}

Caries, Sealant, Prevention, Silver Nanoparticles. 


\section{RESUMEN}

El objetivo del presente estudio fue evaluar la efectividad del sellado marginal y microfiltración de un sellador de fosetas y fisuras con contenido de nanopartículas de plata (AgNPs). Para esto, se realizó un estudio experimental in vitro usando 40 molares temporales extraídos sin caries 0 con caries incipiente. Estos molares fueron divididos en dos grupos: Grupo A (20 molares), a los cuales se les aplicó sellador adicionado con nanopartículas de plata, y Grupo B (20 molares), a los cuales se les aplicó el sellador convencional. Se evaluaron el sellado marginal y la microfiltración. No se encontraron diferencias significativas en el sellado marginal y microfiltración entre el sellador adicionado con nanopartículas de plata y el sellador convencional. Basados en los resultados obtenidos a partir de este estudio concluimos que la adición de AgNPs no altera la adhesión o la resistencia del sellador.

\section{PALABRAS CLAVE}

Caries, Sellador, Prevención, Nanopartículas de plata.

\section{INTRODUCTION}

Dental surfaces with pits and fissures are particularly vulnerable to caries. One of the most widely accepted methods for caries prevention is the use of a pit and fissure sealant (PFS), the function of which is to act as a physical barrier on the occlusal surface, particularly in fissures. The use of PFS has been considered to be an excellent preventive measure against caries. Sealants are substances that can penetrate into microporosities of the previously conditioned enamel, usually with the aid ofan acid. After polymerization, sealants form a continuous and resistant film that, when perfectly adapted and retained, is capable of providing a mechanical barrier that hinders dental plaque accumulation, allowing improvedhygiene (Koyuturk et al, 2008; Kane et al, 2009; Montanari et al, 2008; Lobo et al, 2005; Pardi et al, 2006; Singh and Pandey, 2011).The American Dental Association has established specific criteria for the placement of PFS for caries prevention: a) Sealants should be placed on pits and fissures of children's primary teeth when it is determined that the tooth, or the patient, is at risk of experiencing caries; b) Sealants should be placed on pits and fissures of children's and adolescents' permanent teeth when it is determined that the tooth, or the patient, is at risk of experiencing caries; c) Sealants should be placed on pits and fissures of adults' permanent teeth when it is determined that the tooth, or the patient, is at risk of experiencing caries (Beauchamp et al, 2008).

For many years, researchers have recognized the antimicrobial properties of silver. Recently, this knowledge has been used to create consumer products containing silver nanoparticles (AgNPs), which are the most frequently used nanomaterials in medicine. Silver is a bactericide, and when it is in the form of nanoparticles, its surface area is increased, thus improving the antimicrobial efficiency against 150 types of microorganisms, including those that are drug resistant. Currently, many products containing nanoparticles are available and exhibit various antibacterial capabilities; such products include surgical membranes, antiseptic solutions, surgical dressings, surgical catheters, operating room paint, detergents and food packaging material. The use of these products has been increasing because of excellent results (Kumar et al, 2008; Totaro and Rambaldini, 2009; Kostenko et al, 2010).

Based on these encouraging results, the adhesion of AgNPs to PFS could be an alternative 
for inhibiting the caries formation process, which is a global problem, without affecting the properties of the sealant. The aim of this study was to evaluate the effectiveness of the marginal seal and the degree of microleakage of a pit and fissure sealant supplemented with AgNPs.

\section{MATERIALS AND METHODS}

\section{MANUFACTURING OF AGNPS}

The procedure involved reactions of colloidal solutions with oversaturation of salts and the creation of a precipitate by homogeneous or heterogeneous nucleation. After nucleation, the nanoparticles' growth occurred by diffusion. The concentration gradient, temperature changes, agitation, and surfactants allowed for the modification of the size increment. We produced monodispersed, non-agglomerated particles with a uniform size. First, we prepared a solution of silver, with sodium tetrahydroborate $\left(\mathrm{NaBH}^{4}\right)$ included as a reducing agent. The ratio between silver and the reducing agent was greater than one. After the reaction, we added a stabilizer to control size and uniformity. For the experiment, the entire content of PFS ClinproTM (3M ESPE, St Paul, MN, USA) was extracted from its container and manually mixed with the AgNPs using a spatula creating a homogeneous mixture in a dark room. Later, the mixed material was returned in the original sealant container. The size of the nanoparticles was between $40-60 \mathrm{~nm}$ at a concentration of $6.45 \mu \mathrm{g} / \mathrm{mL}$.

\section{EXPERIMENTAL DESIGN}

An experimental, blind, randomized in vitro study was carried out. A total of 40 freshly extracted primary molars without caries or incipient caries were included in the study. These specimens were cleaned with pumice and a rubber cup, washed with deionized water and dried with air. The teeth were then randomly assigned into two groups of 20 each: Sealants containing AgNPs were applied to Group A (experimental), and conventional sealants were applied to Group B (control). The placement of the sealant on each sample was performed in accordance with the manufacturer's instructions. Prophylaxis was performed with a prophylactic brush with synthetic bristles. Etching was performed by applying 35\% phosphoric acid (3M ESPE, St Paul, MN, USA) to the occlusal surface of the tooth for 20 seconds; it was then rinsed for 15 seconds and dried with air for 15 seconds. Adhesive was applied with a microbrush applicator for 10 seconds and photopolymerized for 30 seconds with a halogen light. Finally, the sealant was applied (conventional and AgNPscontaining) and photopolymerized for 30 seconds. After curing, the margins of the sealants were checked for any failure under a stereomicroscope. In case of failure, the specimens were eliminated and replaced. After the application of the sealant, the teeth were subjected to thermocycling, which consisted of 500 cycles of temperatures ranging from $57^{\circ} \mathrm{C}-37^{\circ} \mathrm{C}-4^{\circ} \mathrm{C}$ for 30 seconds each using water baths. Subsequently, each tooth was covered with two layers of nail varnish. Teeth from both groups were covered with sticky wax on all surfaces. All teeth were immersed in a $0.1 \mathrm{mg} / \mathrm{mL}$ solution of CdSe/ZnS nanoparticles (Lumidot ${ }^{\mathrm{TM}}$; Sigma-Aldrich, St. Louis, MO, USA) (QDs) in ethanol for 4 hours and subsequentlywashed with water.

The dental samples were cut longitudinally, and they were visualized under a confocal scanning laser microscope (CSLM) (Leica DMI 4000B; Wetzlar, Germany). The loss of marginal sealing was determined by examining the penetration or microleakage of QD svia CSLM and measuring the total periphery of the sealant. Penetration was scored using the following values: 0 - no penetration; 1 - the sealant penetrated one third of the entire fissure length (depth); 2 - the sealant penetrated one half of the entire fissure length; 3 - the sealant penetrated the entire fissure length. These measurements were performed on different areas of the molars (Koyuturk et al, 2008; Grande et al, 1998). 


\section{STATISTICAL ANALYSIS}

The marginal seal scores were estimated in both treatments. A non-parametric Mann Whitney's $U$ test was performed to identify statistically significant differences between the groups. The level of significance was set at 0.05 , with a statistical power of $80 \%$.

\section{RESULTS}

To examine marginal sealing, measurements were made using the circumference of the dental occlusal surface (Figure 1). In Group A (experimental), an average loss of 55.74 was observed. In Group B (control), the average was 56.23. There was no significant difference between the two groups $(P>0.05)$ (Table 1). Regarding microleakage, it was found that the CdSe/ZnS nanoparticles penetrated the entirety of the fissure in all samples (Figure 2).

Table 1. Marginal seal measurements in the studied groups.

\begin{tabular}{lcccc}
\hline Group & $\mathbf{N}$ & $\begin{array}{c}\text { Mean } \pm \text { Standard } \\
\text { Deviation }\end{array}$ & Median & Range \\
\hline A & 20 & $55.74 \pm 14.19$ & 55.78 & $35.59-87.30$ \\
B & 20 & $56.23 \pm 16.04$ & 54.19 & $31.91-83.33$ \\
\hline
\end{tabular}

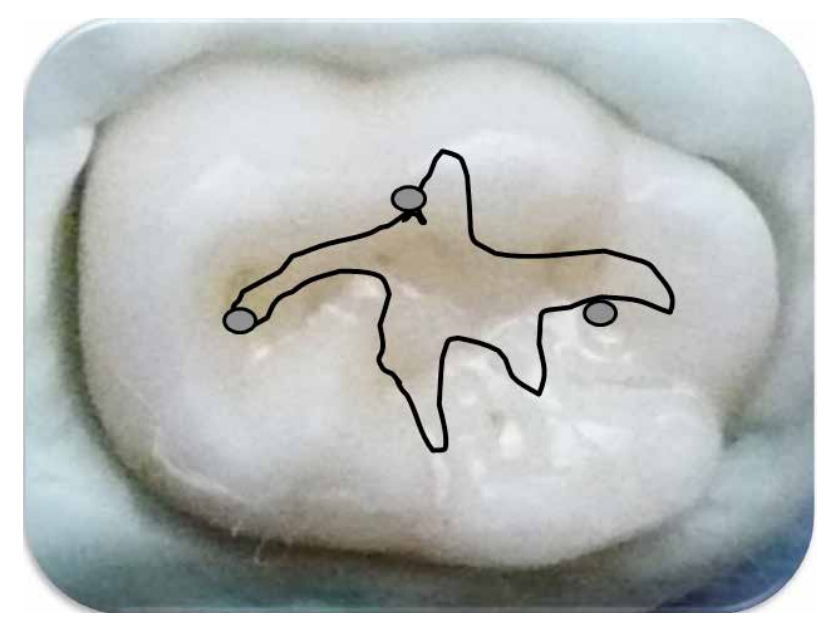

Figure 1. Areas of the molars upon which the measurements were performed.

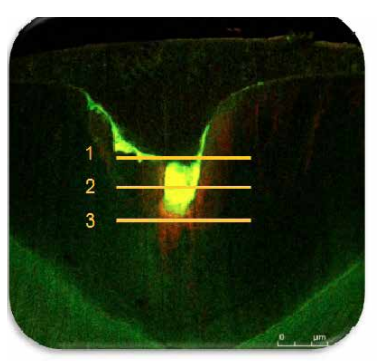

A

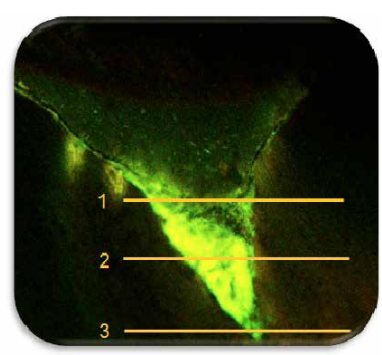

B
Figure 2. Penetration of QDs into the fissure. (A) Experimental group, (B) Control group

\section{DISCUSSION}

The use of PFS is a common practice in pediatric dentistry with the aim of preventing the formation of carious lesions; however, the success of this preventive treatment depends on the application technique. Although the PFS application technique initially appears to be a very simple procedure, over the long term, the clinical success of PFS is directly related to the rigor of this application technique. The addition of AgNPs to PFS can increase the protective effect against the formation of carious lesions. However, to guarantee that the addition of AgNPs to these dental materials does not alter other properties, such as the adhesion or resistance of the sealant, studies are necessary to determine the effectsof these nanoparticles. The results of the present study indicate that the addition of AgNPs to sealants does not alter the marginal seal when compared with the control group. In previous studies we showed that Streptococus mutans, the principal organism associated with caries, is targeted by AgNPs. It has been determined that the minimum inhibitory concentration of AgNPs against Streptococcus mutans is $4.86 \mu \mathrm{g} / \mathrm{ml}$ and the minimum bacteriostatic concentration is 6.25 $\mu \mathrm{g} / \mathrm{ml}$, employing AgNPs of a size of 40 and 60 nm (Hernández-Sierra et al, 2008). Microbiological qualities remain when added to Gantrez, an adhesive used in toothpaste, which does not stain tooth structure (Hernández-Sierra et al, 2010a; Hernández-Sierra et al, 2010b). Also, AgNPs 
toxicity has been discarded in periodontal tissue at a nanoparticle size of 50-100 nm, with no changes in cell viability (Hernández-Sierra et al, 2011).

In the present study, we used a thermocycling method to evaluate aging under in vitro conditions. Thermal changes controlled in a laboratory environment have been used to replicate the oral environment and to imitate the normal aging process (Nikaido et al, 2002; Barclay et al, 2002; Wahab et al, 2003; Frankenberger et al, 2005).

In this study, marginal sealing was determined by the use of QDs. The circumference of the tooth's occlusal surface was measured, and the areas that showed greater fluorescence reflected greater loss of marginal sealing. QD microleakage was also evaluated. QDs were used in these experiments because although methylene blue penetrates fissures, it does not have the same penetration ability as the nanoparticles, which can diffuse to the deepest part of the fissure. Additionally,observation via confocal microscopy allows more complete visibility (fluorescence) and greater accuracy; using this method, we identified microleakage in all the samples of both groups. Our study was performed on primary teeth, which contain wide "V" shaped pits and fissures.Such teeth differ from permanent teeth, in which the fissures are deep and narrow. We selected primary molars for use in this study because diverse studies have reported a high incidence of caries in children in these dental organs (Asselin et al, 2008; Khanna et al, 2009).

The prevalence of dental caries is higher on the occlusal surfaces compared with the smooth surfaces. The morphology of occlusal surfaces makes them an ecological niche for the establishment and development of caries-causing bacteria; additionally, it is difficult to remove food particles from substrates that are close to dental pits and fissures. Due to its morphology, the occlusal surface favors the accumulation and retention of dental biofilm, increasing its vulnerability to carious lesions. The location and anatomy of the occlusal surface also favors the retention and availability of cariogenic substrate, as well as hindering (or rendering impossible) the cleaning of pits and fissures. Currently, research has been focused on designing products that prevent caries, such as pit and fissure sealants (Ahovuo-Saloranta et al, 2013; Deery, 2013). Future clinical studies with close follow-up are needed to evaluate the efficacy and protective effect of pit and fissure sealants containing AgNPs against caries.

\section{CONCLUSION}

No significant differences were observed with respect to marginal seal or microleakage between AgNPs-containing and conventional sealants. Thus, the addition of AgNPs does not alter the adhesion or resistance of the sealant.

\section{REFERENCES}

Ahovuo-Saloranta, A., Forss, H., Walsh, T., Hiiri, A., Nordblad, A., Mäkelä, M., \& Worthington H.V. (2013). Sealants for preventing dental decay in the permanent teeth. Cochrane Database Systematic Reviews,doi: 10.1002/14651858. CD001830.

Asselin, M.E., Fortin, D.,Sitbon, Y., \&Rompré P.H. (2008). Marginal microleakage of a sealant applied to permanent enamel: evaluation of 3 application protocols. Pediatric Dentistry,30:29-33.

Barclay, C.W., Boyle, E.L., Williams, R., \& Marquis, P.M. (2002).The effect of thermocycling on five adhesive luting cements. Journal of Oral Rehabilitation, 29:546-552.

Beauchamp, J., Caufield, P.W., Crall, J.J., Donly, K., Feigal, R., Gooch, B., Ismail, A., Kohn, W., Siegal, M., \&Simonsen, R.; American Dental Association Council on Scientific Affairs. (2008). Evidence-based clinical recommendations for 
the use of pit-and-fissure sealants: a report of the American Dental Association Council on Scientific Affairs. Journal of American Dental Association, 139:257-268.

Deery, C. (2013). Caries detection and diagnosis, sealants and management of the possibly carious fissure. British Dental Journal,214:551-557.

Frankenberger, R., Pashley, D.H., Reich, S.M., Lohbauer, U., Petschelt, A., \&Tay, F.R. (2005). Characterisation of resin-dentine interfaces by compressive cyclic loading. Biomaterials, 26:2043-2052.

Grande, R.H., Ballester, R., Singer, Jda. M., \& Santos, J.F. (1998). Microleakage of a universal adhesive used as a fissure sealant. American Journal of Dentistry, 11:109-113.

Hernández-Sierra, J.F., Galicia-Cruz, 0., Angélica, S.A., Ruiz, F., Pierdant-Pérez, M., \& PozosGuillén, A.J. (2011). In vitro cytotoxicity of silver nanoparticles on human periodontal fibroblasts. Journal of Clinical Pediatric Dentistry,36:37-41.

Hernández-Sierra, J.F., Ruíz, F., CastanedoCázares, J.P., Martinez-Ruiz, V., Mandeville, P., Pierdant-Pérez, M., Gordillo-Moscoso, A., \& Pozos-Guillén, Ade J. (2010(a)). In vitro determination of the chromatic effect of a silver nanoparticles solution linked to the Gantrez S-97 copolymer on tooth enamel. Journal of Clinical Pediatric Dentistry,35:65-68.

Hernández-Sierra, J.F., Ruiz, F., Pena, D.C., Martínez-Gutiérrez, F., Martínez,A.E., Guillén,A. de J., Tapia-Pérez, H., \& Castañón, G.M. (2008). The antimicrobial sensitivity of Streptococcus mutans to nanoparticles of silver, zinc oxide, and gold. Nanomedicine: Nanotechnology, Biology, and Medicine,4:237-240.

Hernández-Sierra, J.F., Salas-López, E.K., MartínezGutiérrez, F., Ruíz, F., Pierdant-Pérez, M.,
Mandeville, P., \& Pozos-Guillén, A.J. (2010(b)). Bactericidal capacity of silver nanoparticles associated with Gantrez S-97 on Streptococcus mutans. Journal of Clinical Pediatric Dentistry, 35:183-185

Kane, B., Karren, J., Garcia-Godoy, C., \& GarciaGodoy, F. (2009). Sealant adaptation and penetration into occlusalfissures. American Journal of Dentistry, 22:89-91.

Khanna, R., Pandey, R.K., Singh, N., \& Agarwal, A. (2009). A comparison of enameloplasty sealant technique with conventional sealant technique: a scanning electron microscope study. Journal of the Indian Society of Pedodontics and Preventive Dentistry,27:158-163.

Kostenko, V., Lyczak, J., Turner, K., \& Martinuzzi, R.J. (2010). Impact of silver-containing wound dressings on bacterial biofilm viability and susceptibility to antibiotics during prolonged treatment. Antimicrobial Agents and Chemotherapy, 54:5120-5131.

Koyuturk, A.E., Kusgoz, A., Ulker, M., \& Yesilyurt, C. (2008). Effects of mechanical and thermal aging on microleakage of different fissure sealants. Dental Materials Journal,27:795-801.

Kumar, A., Vemula, P.K., Ajayan, P.M., \& John, G. (2008). Silver-nanoparticle-embedded antimicrobial paints based on vegetable oil. Nature Materials,7:236-241.

Lobo, M.M., Pecharki, G.D., Tengan, C., da Silva, D.D., da Tagliaferro, E.P., \& Napimoga, M.H. Fluoride-releasing capacity and cariostatic effect provided by sealants. (2005). Journal Oral Science,47:35-41.

Montanari, M., Pitzolu, G., Felline, C., \& Piana, $G$. Marginal seal evaluation of different resin sealants used in pits and fissures. An in vitro study. (2008). European Journal Paediatric Dentistry, 9:125-131. 
Nikaido, T., Kunzelmann, K.H., Chen, H., Ogata, M., Harada, N., Yamaguchi, S., Cox, C.F., Hickel, R., \& Tagami, J. (2002). Evaluation of thermal cycling and mechanical loading on bond strength of a self-etching primer system to dentin. Dental Materials, 18: 269-275.

Pardi, V., Sinhoreti, M.A., Pereira, A.C., Ambrosano, G.M., \& Meneghim,Mde C. (2006). In vitroevaluation of microleakage of different materials used as pit-and-fissure sealants. Brazilian Dental Journal, 17:49-52.

Singh, S., \& Pandey, R.K. (2011). Anevaluation of nanocomposites as pit and fissure sealants in child patients. Journal of the Indian Society of Pedodontics and Preventive Dentistry,29:294-299.

Totaro, P., \& Rambaldini, M. (2009). Efficacy of antimicrobial activity of slow release silver nanoparticles dressing in post-cardiac surgery mediastinitis. Interactive Cardiovascular and Thoracic Surgery,8:153-154.

Wahab, F.K., Shaini, F.J., \& Morgano, S.M. (2003). The effect of thermocycling on microleakage of several commercially available composite Class V restorations in vitro. Journal of Prosthetic Dentistry,90:168-174. 